\title{
Quiste de colédoco con sintomatología obstructiva en embarazada
}

\author{
DOI 10.5377/alerta.v4i3.10936 \\ Celina Lisbeth Solis Ramos ${ }^{1^{*}}$, Julio Alfaro Varela ${ }^{2}$, Mario Interiano Tobar $^{3}$, Gabriel Villa Acevedo $^{4}$, \\ Ethel Rivas Zuleta ${ }^{5}$, Mario Tevez Rivas ${ }^{6}$ \\ 1. Fondo Solidario para la Salud, San Salvador, El Salvador. \\ 2,3,4. Clínica de Cirugía Hepatobiliar del Hospital Médico Quirúrgico, Instituto Salvadoreño del Seguro Social, San Salvador, El \\ Salvador. \\ 5,6. Departamento de Radiología e Imágenes, Instituto Salvadoreño del Seguro Social, San Salvador, El Salvador.
}

${ }^{*}$ Correspondencia

$\square$ celinalisbeth@gmail.com.

(D) $0000-0001-9656-2558$

\begin{abstract}
Resumen
Los quistes de colédoco son poco comunes, en los países occidentales se ha reportado una incidencia de 1 por cada 100 mil nacidos vivos. En países asiáticos, esta incidencia es mayor, 1 por 100 nacidos vivos. Son usualmente diagnosticados durante la infancia y en el $25 \%$ de los pacientes se presentan durante su vida adulta. Es inusual que se presenten durante el embarazo, sobre todo, que se manifieste durante el primer trimestre. Se realizó un informe de caso con presentación inusual del cuadro clínico no causal, de una embarazada en su primer trimestre con sintomatología obstructiva, evolucionando a colangitis. se realizan exámenes de gabinete como ultrasonografía abdominal y exámenes de laboratorio revelando obstrucción, además de realizarse colangioresonancia y ultrasonografía endoscópica dando como resultado quiste de colédoco tipo $1 \mathrm{C}$, se realiza drenaje. Posteriormente al alta hospitalaria, la paciente presenta nuevamente cuadro de colangitis, se realiza drenaje endoscópico, sin embargo, presenta aborto.

Palabras clave

Conducto colédoco, ictericia obstructiva, colangiopancreatografia retrógrada endoscópica, colangitis.
\end{abstract}

\begin{abstract}
Choledochal cysts are rare, in western countries an incidence of 1 per 100,000 live births has been reported. In Asian countries, this incidence is higher 1 per 100 live births. They are usually diagnosed during childhood and in $25 \%$ of patients they present during their adult life. It is unusual for them to occur during pregnancy, especially during the first trimester. A case report was made with an unusual presentation of the non-causal clinical picture, of a pregnant woman in her first trimester with obstructive symptoms, evolving to cholangitis. Cabinet examinations such as abdominal ultrasonography are performed, resulting in type 1C common bile duct cyst. Drainage is performed After discharge from the hospital, the patient presents again with cholangitis, endoscopic drainage is performed, however, she has abortion.
\end{abstract}

Keywords

Common bile duct, jaundice obstructive, cholangiopancreatography, endoscopic retrograde, cholangitis.

\section{Introducción}

El quiste de colédoco es una dilatación congenita de la vía biliar, tiene una incidencia de uno por cada 100 mil nacidos vivos en los países occidentales'. En países asiáticos, esta incidencia es mayor a uno por cada 100 mil nacidos vivos. Son usualmente diagnosticados durante la infancia y en el $25 \%$ de los pacientes se presentan durante su vida adulta'. Es inusual que se presenten durante el embarazo². Los quistes de colédoco representan riesgos para la salud como el parto pretérmino, desarrollo de cáncer del tracto biliar o peritonitis por la ruptura del quiste dilatado inducido por el embarazo ${ }^{3}$. Los síntomas usualmente son inespecíficos ${ }^{3}$. Se presenta ictericia sin causa aparente durante la infancia y dolor abdominal vago; incluso, puede llegar a confundirse con otras patologías propias de la edad. Durante el embarazo, la presentación de ictericia se manifiesta en el segundo y tercer trimestre de embarazo ${ }^{3}$.
G

ACCESO ABIERTO

Coledocial cyst with obstructive symptomatology in pregnant

Citación recomendada: Solis Ramos CL, Alfaro Varela J, Interiano Tobar M, Villa Acevedo G, Rivas Zuleta E, Tevez Rivas M. Quiste de colédoco con sintomatología obstructiva en embarazada. Alerta. 2021;4(3):109-113 DOI: $10.5377 /$ alerta.v4i3.10936

Recibido:

1 de marzo de 2021

\section{Aceptado:}

6 de julio de 2021

\section{Publicado:}

26 de julio de 2021

\section{Contribución de autoría:}

CLSR': diseño y la adquisición de datos. JAV²: concepción del estudio. MIT $^{3}$, GVA4: análisis e interpretación del caso. ERZ ${ }^{5}, M^{2} R^{6}$ : interpretación de imágenes como apoyo diagnóstico y la orientación clínica del caso.

\section{Conflicto de intereses:}

Los autores declaran no tener conflicto de interés. 
El embarazo altera la función de la vesícula biliar, se atribuye a los cambios hormonales por los estrógenos y la progesterona ${ }^{3}$. Estos cambios hormonales influyen en que se presente en las embarazadas el 4,5\% de cuadros de colecistolitiasis asintomática y el 0,05\% de embarazadas llega a cursar con sintomatología ${ }^{4}$. Los quistes de colédoco en las embarazadas representan una amenaza vital para la madre y el feto 3 . El diagnóstico durante el embarazo es difícil, ya que requiere sospecha diagnóstica y auxiliares diagnósticos ${ }^{5}$. Uno de los auxiliares diagnósticos más utilizados es el ultrasonido abdominal, pero su interpretación en el embarazo es difícil debido a la distorsión de la anatomía normal del abdomen y del aumento del tamaño con el útero grávido. Sus síntomas y signos están opacados por los cambios en esta fase, por lo que el diagnóstico puede ser tardío y sus complicaciones pueden poner en peligro a la embarazada 5 .

Se describe el cuadro clínico de una paciente, los síntomas que presentó y cómo se llegó al diagnóstico de la patología en el primer trimestre con diagnóstico de quistes de colédoco, ya que su manifestación en el primer trimestre es rara debido a que los cambios físicos y de órganos internos no llegan a provocar ictericia obstructiva sino hasta el segundo y tercer trimestre del embarazo. El objetivo de la descripción del caso clínico es dar a conocer la importancia de establecer un manejo adecuado en las embarazadas que presentan sintomatología con ictericia obstructiva secundaria a quiste de colédoco en el primer trimestre de embarazo y los métodos diagnósticos utilizados.

\section{Presentación de caso}

Embarazada de 19 años, primigesta que consultó la unidad de emergencia de un hospital nacional, con 13 semanas de gestación, sin antecedentes médicos ni quirúrgicos, ni alergias conocidas. Con historia de dolor abdominal continuo, de moderada intensidad en hipocondrio derecho de tres semanas de evolución, náuseas, vómitos e ictericia conjuntival. Se le indicaron exámenes de laboratorio que reportaron los siguientes valores: bilirrubina total 5,39 mg/ $\mathrm{dL}$, bilirrubina directa $3,54 \mathrm{mg} / \mathrm{dL}$ y bilirrubina indirecta $1,85 \mathrm{mg} / \mathrm{dL}$. Inicialmente se realiza una ultrasonografía abdominal, que reportó una colelitiasis, un quiste de colédoco y leve esteatosis hepática. Se indicó su ingreso hospitalario y tratamiento con amoxicilina/ácido clavulánico 500/125 mg vía oral cada 8 horas, sulfato ferros más ácido fólico, antieméticos y antihistamínicos H2. Cuatro días posteriores se refirió al hos- pital de segundo nivel de atención del Instituto Salvadoreño del Seguro Social, donde se actualizaron exámenes, que reportaron bilirrubina total 9,09 mg/dL, bilirrubina directa $8,53 \mathrm{mg} / \mathrm{dL}$, bilirrubina indirecta 0,56 $\mathrm{mg} / \mathrm{dL}$ y cociente aspartato transaminasa / alanina aminotransferasa 136/ $256 \mathrm{U} / \mathrm{L}$ y una ultrasonografía abdominal en la que se describió dilatación de la vía biliar intra y extrahepática, un quiste gigante de colédoco 5,9 × 5,7 cm, por lo que se indicó su traslado al Hospital Médico-Quirúrgico (HMQ) para el manejo adecuado.

En el HMQ se realizó una ultrasonografía abdominal que reportó la dilatación de la vía biliar intra y extrahepática, colédoco dilatado, aspecto quístico en tercera y cuarta porción $6,9 \times 6,61 \mathrm{~cm}$. Se concluyó en un quiste de colédoco tipo 1. Se realizó una colangiopancreatografía retrógrada endoscópica (CPRE), que resultó fallida debido a que la papila de Váter fue de difícil canulación; se realizó una esfinterotomía de precorte que evidenció drenaje de bilis, pero no se logró identificar el orificio y se observó edema de papila. Los exámenes posteriores al CPRE reportaron bilirrubina total de $8,26 \mathrm{mg} / \mathrm{dL}$, bilirrubina directa de $7,49 \mathrm{mg} / \mathrm{dL}$ amilasa $567 \mathrm{U} / \mathrm{L}$, lipasa 200 $\mathrm{U} / \mathrm{L}$.

El noveno día de hospitalización se realizó una colangioresonancia magnética nuclear abdominal (Figura 1), en la que se observó el conducto colédoco marcadamente dilatado en la totalidad de su trayecto, de aspecto ovoide, de 7,3 x 7,6 cm, sin identificar defectos de llenado que sugieran cálculos. No se logró identificar su porción distal; no fue posible evaluar la ampolla de Váter por este método. Se identificó dilatación retrógrada generalizada del conducto cístico, conducto hepático común y radículos hepáticos que medían 1,6 y $1,5 \mathrm{~cm}$ del lado derecho e izquierdo, respectivamente. El conducto pancreático no se observó dilatado. Se concluyó en un quiste de Todani $1 \mathrm{C}$ con dilatación generalizada de la vía biliar intrahepática y el conducto cístico.

Al día once de hospitalización, la paciente evolucionó con una colangitis aguda supurada y con sintomatología obstructiva secundaria a quiste de colédoco Todani $1 \mathrm{C}$ con dilatación generalizada de la vía biliar intrahepática y del conducto cístico por colangioresonancia magnética nuclear abdominal. Se le realizó una ultrasonografía endoscópica en la que se describió una dilatación del árbol biliar intrahepático. Se continuó hasta una dilatación quística de 68 × $70 \mathrm{~mm}$ de hepatocolédoco con escasa cantidad de sedimento, co- 
lédoco intrapancreático de calibre normal. Se le explicaron las alternativas de tratamiento médico y las principales complicaciones de su condición. Se decidió dar tratamiento médico, con ceftriaxona $1 \mathrm{~g}$ vía endovenosa cada 12 horas y ranitidina 50 mg vía endovenosa cada 12 horas y control con exámenes. Las bilirrubinas descendieron hasta sus valores normales y se decidió el alta hospitalaria. Se indicaron controles en la consulta externa, con la especialidad de cirugía endoscópica cada mes y con la de cirugía hepatobiliar cada dos semanas, así como evaluación de los exámenes de laboratorio en cada control. Se le indicó que si el cuadro clínico de ictericia obstructiva empeoraba, se manejaría vía endoscópica hasta programarse cirugía en posparto.

La paciente asistió al HMQ para realización de procedimiento endoscópico un mes posterior al alta hospitalaria; sin embargo, se diagnosticó nuevamente un cuadro de colangitis, con valores de bilirrubinas de $19 \mathrm{mg} / \mathrm{dL}$. Se solicitó la evaluación por ginecología y se realizó una ultrasonografía obstétrica que reportó un aborto. Se indicó el ingreso hospitalario y se realizó el drenaje endoscópico por CPRE más colocación de stent biliar. Posteriormente, se trasladó al Hospital Materno Infantil 10 de Mayo, donde se realizó un legrado instrumental, sin complicaciones y luego se indicó tratamiento médico con ceftriaxona $1 \mathrm{~g}$ cada 12 horas por vía endovenosa, ranitidina 50 mg cada 12 horas por vía endovenosa, metoclopramida $10 \mathrm{mg}$ cada 8 horas por vía endovenosa y acetaminofén 500 mg cada 6 horas por vía oral. Además, se realizaron exámenes en serie hasta disminuir valores de bilirrubina a lo normal; se indicó el alta hospitalaria posterior a diez días de estancia hospitalaria.

Un día posterior al alta hospitalaria se indicó el ingreso en la unidad de cuidados intermedios del $\mathrm{HMQ}$, con el diagnóstico de colangitis grado III. Recibió tratamiento con piperacilina/tazobactam 4,5 g cada 6 horas por vía endovenosa durante 10 días, omeprazol $40 \mathrm{mg}$ por ampolla, una ampolla cada 12 horas por vía endovenosa, metoclopramida $10 \mathrm{mg}$ cada 8 horas por vía endovenosa y se realizaron exámenes que reportaron un aumento en los niveles de bilirrubina. Se realizaron exámenes seriados, con bilirrubinas en reducción y una ultrasonografía abdominal que describió un quiste de colédoco con lodo biliar en su interior y dilatación del conducto colédoco 0,74 cm. Al completar un mes de hospitalización, se reportaron bilirrubinas con valores normales y se indicó el alta

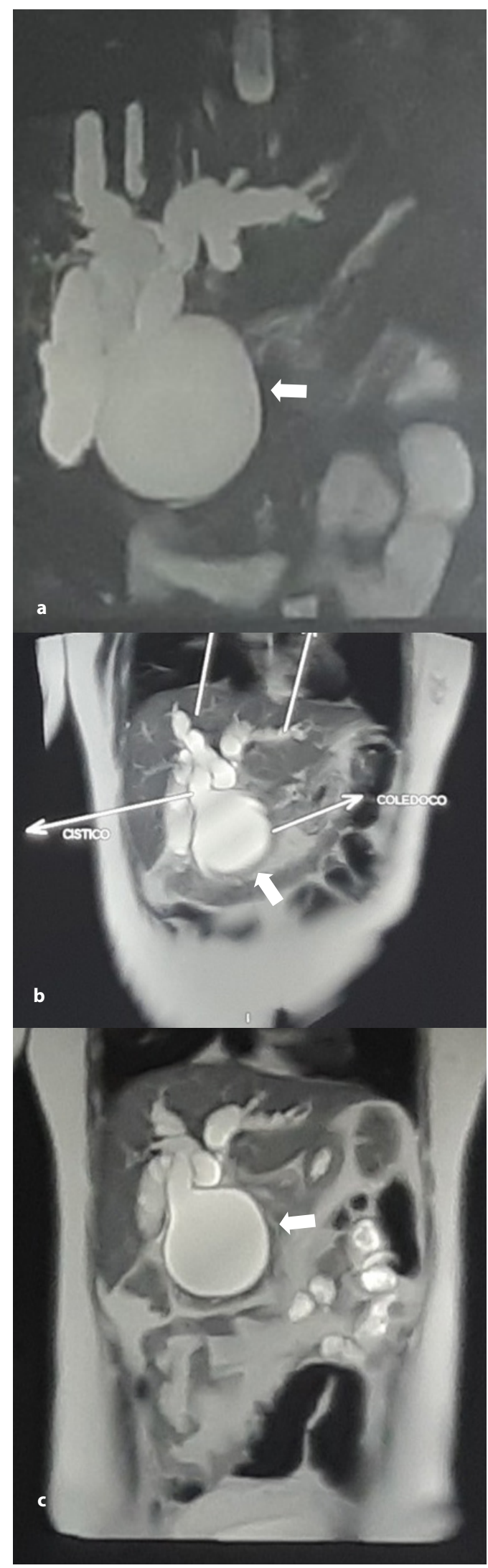

Figura 1. Resonancia Magnética Abdominal.

Figura 1a: Colangiograma, se observa aumento del diámetro y tortuosidad de la vía biliar intrahepática, hasta el conducto hepático común; ausencia de vesícula biliar. El conducto colédoco con dilatación fusiforme que sobrepasa la unión con el conducto cístico (Quiste de colédoco Todani 1C). Sin defectos de llenado que sugieran cálculos. Figura 1 b: Imagen coronal secuencia True-Fisp. Figura 1c: Imagen coronal. 
hospitalaria e indicó realizar la resección del quiste del colédoco de manera electiva. Luego de cuatro meses se realizó la resección de quiste de colédoco con derivación biliodigestiva por cirugía abierta, manteniendo controles en consulta externa con cirugía hepatobiliar.

\section{Discusión}

Las manifestaciones clínicas de ictericia obstructiva secundaria a quistes de colédoco en las embarazadas durante el primer trimestre es una manifestación clínica de rara presentación; sin embargo, se presenta frecuentemente en mujeres asiáticas. La importancia del caso radica en el cuadro clínico atípico, el escaso reporte de casos en la literatura y su controversial manejo. El diagnóstico final se apoyó a través de estudios de gabinete como la colangioresonancia magnética nuclear abdominal, el CPRE ${ }^{6}$ y la ultrasonografía endoscópica. La paciente presentó nuevamente cuadro de colangitis, se le realizó drenaje endoscópico, sin embargo, a pesar de realizarse tratamiento médico, presentó aborto.

Los quistes biliares pueden clasificarse según su localización en extrahepáticos e intrahepáticos; por extensión, en segmentario o completo; por tamaño y forma, quístico, sacular o fusiforme y la mayoría se basan en aspectos anatómicos. La clasificación de Todani y cols. es la clasificación más utilizada, ya que es sencilla, fácil de aplicar y es una de las bases que guía el proceder terapéutico ${ }^{7}$. Se pueden tener complicaciones como colangitis, pancreatitis, cálculos y malignidad que pueden desarrollarse si no se diagnostican los quistes de colédoco ${ }^{8}$. Su etiología es probablemente multifactorial ${ }^{9}$.

Los quistes de colédoco resultan ser de importancia para la población y sobre todo entre pediatras, gastroenterólogos, radiólogos y cirujanos, debido a que su presentación puede confundirse con otras patologías como la clínica de la coledocolitiasis y el diagnóstico puede tardar en confirmarse si no se realiza de manera oportuna a través de estudios de imagen que orientan al diagnóstico. La presentación clínica y el manejo dependerá del tipo de quiste biliar ${ }^{10}$.

Las enfermedades biliares durante el embarazo no son infrecuentes y son generalmente secundarias a enfermedad litiásica. La incidencia de quistes de colédoco es de 1:100 000-150 000 en países de la región occidental ${ }^{11}$.

Según reportes de casos, en el periodo comprendido entre el 01 de enero al 31 de diciembre de 2019 sobre obstrucción del conducto biliar (K83.1), a nivel nacional sin diferenciar edad o sexo, fueron de 172 casos; para consultas generadas en el mismo periodo en el rango de 15 a 19 años, se generó un total de 11 consultas sobre cálculo de conducto biliar con colangitis (k80.3), tanto consultas por primera vez como subsecuentes. No se disponen de datos sobre embarazadas con ictericia obstructiva secundaria a quistes de colédoco en el Sistema de Morbi-Mortalidad en la Web (SIMMOW) ni tampoco se dispone de literatura nacional acerca de embarazadas con ictericia secundaria a quistes de colédoco ${ }^{12}$.

\section{Conclusión}

Los quistes de colédoco resultan un reto para especialidades médicas como cirujanos hepatobiliares, endoscopistas, uciólogos, metabólicos, nutriólogos y se integran los ginecólogos-uciólogos cuando la manifestación se presenta en embarazadas, debido a que es un desafío diagnóstico y terapéutico para un amplio espectro de la profesión médica ${ }^{9}$. Los quistes de colédoco en el embarazo y su tratamiento no solo es rara $^{13}$, sino que los signos y síntomas clínicos de la condición clínica se ve alterada y, en ocasiones, enmascarado por los cambios fisiológicos que ocurren durante el embarazo. Eso da como resultado que en la mayoría de casos el diagnóstico se retrasa hasta que los pacientes presentan complicaciones potencialmente mortales para el feto y la madre ${ }^{14}$. Existen algunos enfoques más conservadores que sugieren el drenaje externo del quiste de colédoco para pacientes embarazadas $^{15}$, sin embargo, se recomienda su valoración en un equipo multidisciplinario coordinado.

Debido a las posibles complicaciones que genera la manifestación clínica de los quistes de colédoco, se ha sugerido la realización de drenaje percutáneo ${ }^{16}$ en todos los casos y diferir la cirugía hasta después del parto. Algunos estudios reportan buenos resultados para cirugías en dos tiempos, en esta se realizan colecistectomía percutánea bajo guía ecográfica y succión del quiste de colédoco y posteriormente se lleva a cabo una derivación biliodigestiva. Existen otros estudios donde se menciona un abordaje por medio de drenaje transhepático percutáneo, en el manejo de un quiste de colédoco tipo 17,18.

Actualmente no existe un algoritmo que defina el manejo ideal en casos como estos cuando la manifestación clínica es a partir del primer trimestre de embarazo.

Debe existir un consenso multidisciplinario entre las especialidades de ginecología, cirugía endoscópica, cirugía hepatobiliar y médicos radiólogos, para definir el manejo adecuado que prevenga, disminuya o puedan concretar un tratamiento específico a 
este tipo de cuadros clínicos protegiendo la vida de las embarazadas y la del feto.

\section{Aspectos éticos}

Para la presentación de este caso, se le solicitó a la paciente el consentimiento informado y se respetaron los principios de intimidad y dignidad según las pautas de Helsinki.

\section{Agradecimiento}

Autores declaran no tener agradecimientos.

\section{Financiamiento}

Autores declaran no tener fuente de financiamiento.

\section{Referencias bibliográficas}

1. Yamaguchi M. Congenital choledochal cyst. Analysis of 1,433 patients in the Japanese literature. Am J Surg. 1980;140(5):653-657. DOI: 10.1016/0002-9610(80)90051-3

2. Furuhashi S, Takamori H, Nakahara O, Ikuta Y, Tanaka H, Horino K, Baba H. Choledochal cyst during pregnancy: case report and literature review of treatment. Clin. J. Gastroenterol. 2013;6(4):326-328. DOI: 10.1007/s12328-013-0389-7

3. Martínez-Ordaz JL, Morales-Camacho M, Centellas-Hinojosa, Roman-Ramirez E, Romero-Hernandez T, De la Fuente-Lira M. Quiste de colédoco y embarazo. Reporte de 3 casos y revisión de la bibliografía. Cir. 2016;84(2):144-153. DOl: 10.1016/j. circir.2015.06.017

4. Guzmán BP, Heredia R, Niño de Guzmán $\mathrm{O}$, Verduguez N. Colecistitis aguda en el embarazo. Gac. Medica Boliv. 2005;28(2):4249. Disponible en: $\underline{\text { http://www.scielo.org.bo/ }}$ scielo.php?script=sci_arttext\&pid=S101229662005000200008\&lng=es.

5. Wu D-Q, Zheng L-X, Wang Q-S, Tan W-H, Hu S-J, Li P-L. Choledochal cysts in pregnancy: case management and literature review. World J. Gastroenterol. 2004;10(20):30653069. DOI: 10.3748/wjg.v10.i20.3065

6. Crisanto-Campos BA, Trejo-Ávila ME, ArceLiévano E, Moreno-Portillo M. Resección laparoscópica de quiste de colédoco. Informe de dos casos con seguimiento a mediano plazo. Cir. gen. 2018;40(3):200-205. Disponible en: $\underline{\text { http://www.scielo.org.mx/ }}$ scielo.php?script=sci arttext\&pid=S140500992018000300200\&lng=es.

7. Todani T, Watanabe Y, Toki A, Morotomi Y. Classification of congenital biliary cystic disease: special reference to type Ic and IVA cysts with primary ductal stricture. J
Hepatobiliary Pancreat Surg. 2003;10(5):340344. DOI: 10.1007/s00534-002-0733-7

8. Escobar H. LA, Esponisa Vasquez JP. Anomalías quísticas congénicas de la via biliar: Aproximación diagnóstica mediante resonancia magnética. Rev. Colomb. Radiol. 2016;27(4):4556-4561. Disponible en: http:// contenido.acronline.org/Publicaciones/ RCR/RCR27-4/04 Anomalias.pdf

9. Lewis VA, Adam SZ, Nikolaidis P, Wood C, Wu JG, Yaghmai V, Miller FH. Imaging of choledochal cysts. Abdom. Imaging. 2015;40(6):1567-1580. DOI: 10.1007/s00261015-0381-4

10. Jabłońska B. Biliary cysts: Etiology, diagnosis and management. World J. Gastroenterol. 2012;18(35):4801-4810. DOl: 10.3748/wjg. v18.i35.4801

11. Conway WC, Campos GMR, Gagandeep S. Choledochal cyst during pregnancy: The patient's first pregnancy was complicated by a congenital anomaly. Am. J. Obstet. Gynecol. 2009;200(5):588.e1-588.e2. (Images in Osbtetrics). DOl: 10.1016/j. ajog.2009.01.026

12. Hewitt PM, Krige JE, Bornman PC, Terblanche J. Choledochal cyst in pregnancy: a therapeutic dilemma. J. Am. Coll. Surg. 1995;181(3):237-240. Disponible en: https:// pubmed.ncbi.nlm.nih.gov/7670683/

13. Wig JD, Goenka MK, Chawla YK, Nagi B. Cholangitis secondary to choledochal cyst in pregnancy and puerperium. J. Clin. Gastroenterol. 1997;25(2):489-491. DOI: 10.1097/00004836-199709000-00023

14. Mackillop L, Williamson C. Liver disease in pregnancy. Postgrad. Med. J. 2010;86(1013):160-164. DOI: 10.1136/ pgmj.2009.089631

15. Jia B, Tan L, Jin Z, Liu Y. Duel-stage treatment for biliary cysts with cholangitis during pregnancy. Pak. J. Med. Sci. 2017;33(2):483487. DOI: 10.12669/pjms.332.12148

16. Lipton A, Carlan SJ, Teixeira A, Locksmith G. Biliary cyst in pregnancy managed by percutaneous drainage: a case report. J. Reprod. Med. 2013;58(7-8):357-360. Disponible en: https://pubmed.ncbi.nlm nih.gov/23947090/

17. Nasu K, Matsuki S, Kawano Y, Miyakawa I, Nakashima K, Anai H. Choledochal cyst diagnosed and conservatively treated during pregnancy. Am. J. Perinatol. 2004;21(8):463-468. DOI: 10.1055/s-2004835963

18. Gómez Bravo MA, Bernal Bellido C, Álamo Martínez J, Suárez Artacho G, Marin Gómez LM, Cepeda Franco C, Padillo Ruiz FJ. Quiste de colédoco en el paciente adulto. In: Guías clínicas de la asociación Española de Cirujanos. Vol. 1. 2nd ed. Madrid, España: Aran; 2018. pp. 149-156. 